\title{
A Low-Cost PV Emulator using Labview and Arduino
}

\author{
Suganthi K, Sundararaman K, Venkatakrishnakumar V
}

\begin{abstract}
A solar panel emulator is a programmable power supply which mimics the characteristics of a solar panel and can be used under laboratory conditions. This paper proposes the design of an economical solar panel emulator using LabView software and its implementation using Arduino. The proposed emulator consists of a flyback converter with a MOSFET driver which brings out the characteristics of the desired PV panel. The characteristic curves are generated using LabView software and $P W M$ signal is generated in hardware. This PWM signal drives the MOSFET which in turn operates the flyback converter. The proposed system is simulated using MATLAB software and a prototype of the proposed system is implemented using Arduino UNO R3.
\end{abstract}

Keywords : Arduino, LabView, PV emulator, Solar simulator.

\section{INTRODUCTION}

Solar energy based on photovoltaic panels have now been widely accepted as one of the main sources of our energy requirement since it is available widely and is free of cost. India is particularly blessed in this regard as most areas in this country have sunlight all through the year. Hence the population of stand-alone and grid-connected converters based on PV panels is increasing exponentially in India.

The photo-voltaic panel which converts the solar energy in to electrical energy has a life expectancy of more than 20 years. But the overall reliability also depends on other equipment which is part of the system. The converters and inverters which harvest the solar energy and feed to the grid have to be tested under different climatic and load conditions to obtain the best performance and also to improve their reliability. As the equipment rating increases, actual field testing is almost impossible. The solar energy being weather-dependent, realistic field testing for various radiation and temperature conditions and for different levels of panel shading with a varying load, would take a fairly long time. Hence solar photovoltaic emulators are almost a necessity for testing equipment associated with a solar system.

Solar panel emulator could be implemented either in hardware or as a software program such that it enables

Revised Manuscript Received on December 30, 2019.

* Correspondence Author

Suganthi K, Assistant Professor, Sri Venkateswara College of Engineering, Chennai, India

K. Sundararaman, Professor, Rajalakshmi Institute of Technology, Chennai, India.

Venkatakrishnakumar V, Rajalakshmi Institute of Technology, Chennai, India.

(C) The Authors. Published by Blue Eyes Intelligence Engineering and Sciences Publication (BEIESP). This is an open access article under the CC BY-NC-ND license (http://creativecommons.org/licenses/by-nc-nd/4.0/) imitation of the functions of a PV panel. A PV array will be large, expensive and the output power will depend on variable environmental conditions such as temperature and irradiance. A PV emulator is a much more flexible solution as it is efficiently sized, less expensive and has a programmable output. The emulator can be programmed to simulate any weather condition that we would like to test. A PV emulator is like a test instrument as it is efficiently sized to be installed into a standard test rack. The emulator should generate the same I-V characteristics as a normal solar panel of any particular manufacturer and at any particular environmental condition. The environment would again depend on the location of the panel, the season of the year and the particular time of the day.

It should be possible to implement partial shading of the solar panel. Light intensity should be adjustable from $0 \%$ to $100 \%$. It should be possible to configure light intensity curves which change over time. The current operating point should be graphically represented at its position on photovoltaic characteristic and it should measure and display electrical variables. PV emulator would be highly useful if for example someone wants to try out a new algorithm for maximum power point tracking. Similarly if someone has developed a new inverter which needs to be tested along with a PV panel, the emulator could come handy. Applications are also possible for battery charge controller or for smart grids. The emulator is required to have identical current-voltage characteristics as the actual solar panel so that meaningful test results can be obtained. Apart from steady state characteristics, transient response also becomes important if the load or the weather is varying sharply.

Reference [1] presented an economical solar photovoltaic emulator optimized for MPPT evaluation. However the design is optimized for a single PV array and cannot be used where wide control of characteristics is required. Reference [2] developed an Altera Cyclone III FPGA based PV emulator which emulates the I-V characteristics of a PV panel with a dc-dc converter. The model can take care of variation in irradiance and temperatures. Reference [3] developed a photovoltaic (PV) emulator using a graphical user interface like LabView in conjunction with a dc power supply which can be programmed. The interfacing is very easy and this has a wide range of control. However, it is custom-built and relatively expensive. Reference [4] proposed a 150W accurate, low-cost and light-weight PV emulator which can accommodate a series-parallel reconfiguration of the PV panels. It is galvanically isolated using a high-frequency transformer 
A flyback converter is used for generating the voltage output. Reference [5] suggested a flexible low-cost solar emulator which derives PV parameters not from the data sheet but from the analytical models of several photovoltaic cells. PV cell degradation and the effects of partial shading that may occur on the panel are also incorporated in to the model.

Labiew with readily available power supply was used to generate the emulated output.

Reference [6]) designed and implemented a 80W solar panel emulator based on diode approximation model. It is claimed that component usage is minimized leading to lower cost of the emulator.

Reference [7] presented a solar emulator developed using FPGA. AN artificial neural network was trained using Matlab and mentor graphics framework was used to obtain an analog model of the solar panel. Reference [8] proposed a 150W buck-boost based converter implementation of MPPT for off-grid PV applications. Hardware and software protections are incorporated.

Reference [9] proposed a MPPT tracker with a simple Photovoltaic (PV) simulator which is circuit-based. The simulator is based on an equivalent circuit with a single diode. As compared to the solar array simulators available commercially, this simulator is claimed to be cost-competitive. But it has a disadvantage that direct interfacing of test object is difficult. Reference [10] proposed a solar emulator based on a buck converter with in-built power factor correction. The PV characteristics are obtained based on lookup tables. The buck converter with its built-in power factor correction (PFC) mimics the panel behaviour at different irradiance conditions and for different temperatures. Design and simulation results using Matlab were presented. In this work, the I-V characteristic curves of the chosen solar panel are generated using LabView and it is implemented in hardware at a low cost using a flyback converter driven by an Arduino board. Hence it is ideally suited for academic environments where cost considerations are vital.

This paper is organized as follows: The operation of the system is outlined in Section II. Section III covers the design aspects and Section IV brings out the simulation results. Section $\mathrm{V}$ discusses the hardware implementation and Section VI concludes.

\section{OPERATION OF THE SYSTEM}

For designing a solar panel emulator, the characteristic curves of the solar panel have to be generated by some way. In this work, LabView has been chosen as the software platform for generating the characteristic curves as this graphical interface is flexible and easy to use. It can be interfaced with any third party system and is easily interfaced with external hardware. To reduce the overall cost and complexity of coding, Arduino Uno is chosen for the controller due to its low cost and ease of implementation. It allows programming and serial communication using USB cable itself. It operates in an open source environment and is very suitable for real-time applications.

Flyback converter has been chosen as the topology for the power supply since it is the simplest and most common among the topologies for low-power applications which also need isolation. It is also cost-effective. Flyback topology is just an extension of the buck-boost topology that is isolated by using a transformer. The transformer not only provides isolation, but the output voltage can be changed by adjusting the turns ratio. Multiple outputs are also possible.

A current sensor is connected in series with the output side of flyback converter and the load. This is used to sense the current flow in the circuit, which is the output load current. This sensed current value will be passed to the Arduino Uno and then through the serial USB port, it will be received by the PC with LabView for performing required calculations. The voltage sensor senses the voltage drop across the load and converts it into a signal which will be received by the Arduino. The Arduino will decode the signal and then send it to the PC with LabView for further calculations. A resistive load has been considered.

As the characteristic curves are to be generated in the LabView, the solar panel characteristics are to be given as input to the working environment. A Solarex MSX-60 panel has been chosen whose characteristics are obtained from its datasheet listed in Table I.

Table- I: Solarex Msx-60 Panel characteristics

\begin{tabular}{|l|l|}
\hline Parameters & Values \\
\hline Maximum power (Pmax) & $60 \mathrm{~W}$ \\
\hline Voltage @ Pmax (Vmp) & $17.1 \mathrm{~V}$ \\
\hline Current @ Pmax (Imp) & $3.5 \mathrm{~A}$ \\
\hline Guaranteed minimum Pmax & $58 \mathrm{~W}$ \\
\hline Short-circuit current (Isc) & $3.8 \mathrm{~A}$ \\
\hline Open-circuit voltage (Voc) & $21.1 \mathrm{~V}$ \\
\hline
\end{tabular}

The PC with LabView will generate the required characteristic curves of the solar panel required. The data is fed as input via the front panel graphical user interface (GUI) of LabView. The values of characteristic curves are sent to the Arduino as a look up table, using which the Arduino generates the PWM output at specific duty cycle depending upon the data. This PWM is applied to the MOSFET switch of the flyback converter. The flyback converter then converts the $12 \mathrm{~V}$ dc into the required output voltage based on the switching of the MOSFET. The output of flyback converter is applied to the load which is assumed to be resistive. The load voltage and current is sensed by the corresponding sensors and the data is sent to Arduino.

The received data will be sent to PC, where the data will be used to calculate and plot the operating point of the load in the characteristic curve of solar panel. All the results can be seen clearly in the LabView GUI screen in PC.

\section{DESIGN CONSIDERATIONS}

For the flyback converter, the peak value of the primary current and secondary currents and also the duty cycle are dependent on the turns ratio. The circuit in Fig. 1 shows the flyback converter used in the emulator. 


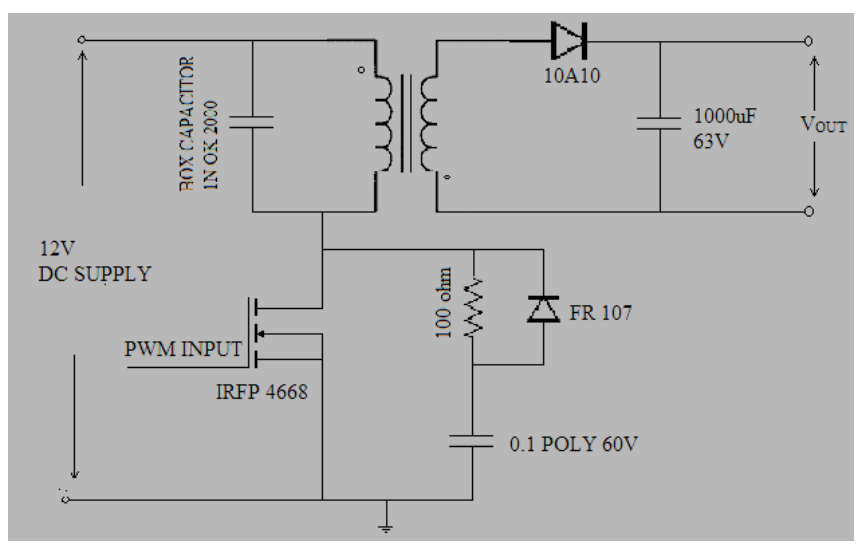

Fig. 1 .Flyback Converter Circuit Diagram

Table- II: Design Parameters

\begin{tabular}{|l|l|}
\hline Input voltage (dc) Vin & $12 \mathrm{~V}$ \\
\hline Output voltage (dc) Vout & $30 \mathrm{~V}$ \\
\hline Output current (dc) Iout & $6 \mathrm{~A}$ \\
\hline Switching frequency & $30 \mathrm{KHz}$ \\
\hline
\end{tabular}

The expressions used in the design are as follows:

Time period, $\mathrm{T}=\frac{1}{f}[$ second $]$

Inductance, $\mathrm{L}=\frac{\left(V_{\text {in }(\max )} D_{(\min )}\right)^{2} T}{2 P_{\text {in }(\min )}}$,

Min duty ratio, $\mathrm{D}_{\min }=\left(\frac{V_{\text {in }(\min )}}{V_{\text {in }(\max )}}\right) D_{(\max )}$

Maximum on time, $\mathrm{t}_{\mathrm{on}(\max )}=T D_{(\max )}$

Max off time, $\mathrm{t}_{\text {off(max) }}=T\left(1-D_{(\min )}\right)$

Min output power $=I_{o 1(\min )}\left(V_{o 1}+V_{d}\right)$

$+I_{o 2(\min )}\left(V_{o 2}+V_{d}\right)+\ldots$.

Inductor $\Delta \mathrm{I}=\frac{\left(T V_{\text {in }(\min )} D_{(\max )}\right)}{L}$

Inductor $\mathrm{I}_{(\mathrm{pk})}=\left(\frac{I_{\text {in }(\max )}}{D_{\max }}\right)+\left(\frac{\Delta I}{2}\right)$

The N- channel Enhancement mode MOSFET (IRFP4668) is used as the switching device for the proposed inverter. The switch operates with a positive input voltage and its high input impedance makes interfacing easy with any driver circuit that supplies a positive voltage. The snubber circuit components are designed using the following equations:

$C=\frac{I_{o} t_{s}}{2 E_{o}}$

$R=\frac{2}{t_{\text {onmin }} C_{s}}$

\section{SIMULATION}

A simulation of the system was done using Matlab for different temperatures and irradiances and the I-V characteristics were plotted. The changes in current vs voltage (I-V) characteristic and power vs voltage $(\mathrm{P}-\mathrm{V})$ curves with changes in irradiances are shown in Fig. 2 \& 3.

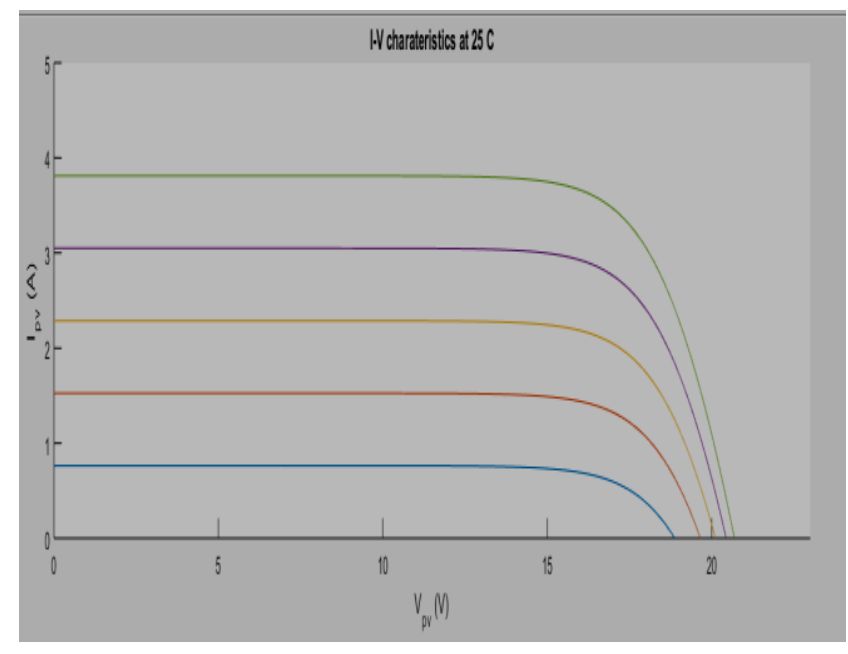

Fig. 2 .I-V characteristics with changes in irradiance

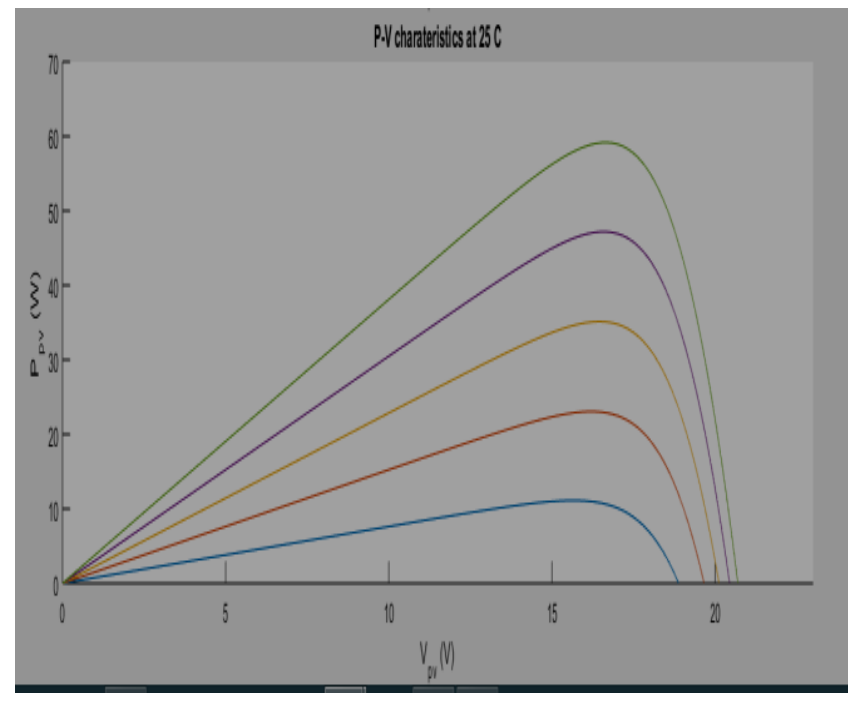

Fig. 3 .P-V characteristics with changes in irradiance

Similarly the variations in $\mathrm{I}-\mathrm{V}$ and $\mathrm{P}-\mathrm{V}$ characteristics due to changes in temperature are illustrated in Fig. 4 and Fig. 5.

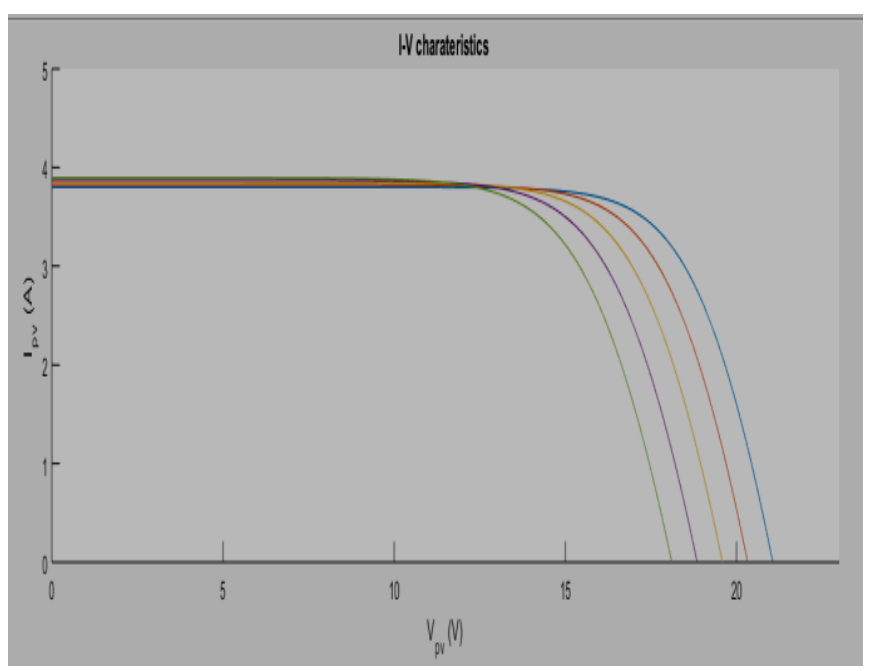

Fig. 4 .I-V characteristics with changes in temperature

Published By:

Blue Eyes Intelligence Engineering

DOI: 10.35940/ijeat.B3009.129219

Journal Website: www.ijeat.org 


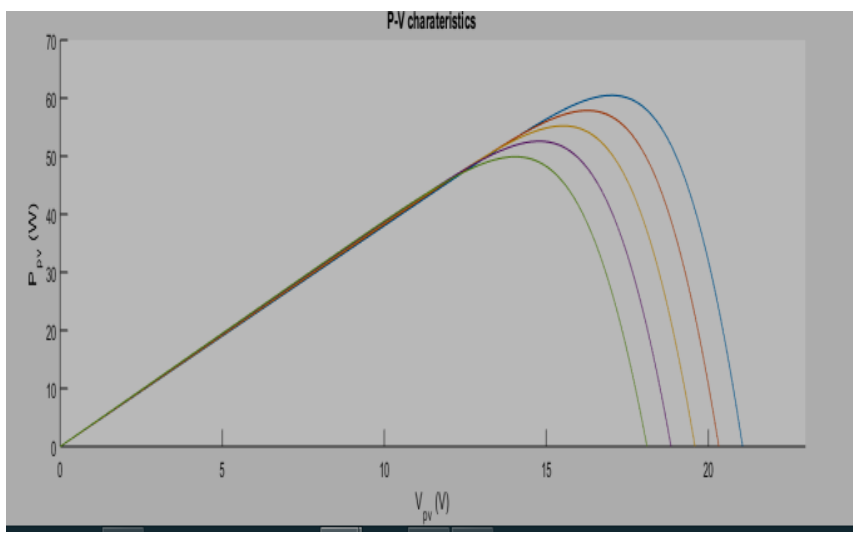

Fig. 5. P-V characteristics with changes in temperature

Table- III: Design values of flyback transformer \& snubber

\begin{tabular}{|c|c|}
\hline Parameters & Values \\
\hline $\mathrm{T}$ & $33.3 \mathrm{us}$ \\
\hline $\mathrm{T}_{\text {on }}$ & $25 \mathrm{us}$ \\
\hline $\mathrm{P}_{\mathrm{o}}$ & $155 \mathrm{~W}$ \\
\hline $\mathrm{P}_{\text {omax }}$ & $155 \mathrm{~W}$ \\
\hline $\mathrm{I}_{\text {inmax }}$ & $21.52 \mathrm{~A}$ \\
\hline $\mathrm{P}_{\text {inmax }}$ & $172 \mathrm{~W}$ \\
\hline $\mathrm{L}$ & $3.5 \mathrm{uH}$ \\
\hline $\mathrm{Np} / \mathrm{Ns}$ & 0.4 \\
\hline Snubber resistance & $100 \Omega$ \\
\hline Snubber capacitance & $0.1 \mathrm{uF}$ \\
\hline
\end{tabular}

\section{HARDWARE IMPLEMENTATION}

The hardware implementation of the proposed design was done using LabView, ARDUINO UNO R3 and flyback converter. TLP 250 was used for driving the power Mosfet. This along with a dc source, diodes and resistors constitute the driver circuit. The TLP photo-couplers can directly drive the gates of IGBTs and power MOSFETs. Only a gate resistor needs to be added.

The hardware was implemented using Arduino UNO controller unit, flyback converter, sensors, driver circuit, resistive load and power supply unit. IRFP 4668 Mosfet which was readily available was used for the switch and FR107 and 10A10 were used for the diodes.

The complete hardware interconnection diagram is shown in Fig. 6 and the hardware implementation images are displayed in Fig. 7 to Fig. 9. Fig. 7 shows the flyback converter board the hardware circuit components can be viewed in Fig. 8. The complete hardware circuit with interconnections is shown in Fig. 9. The panel characteristic as generated by LabView is shown in Fig. 10. Fig. 11 and Fig. 12 show the voltages at open circuit condition, generated at 0.2 and 0.5 irradiances respectively. The corresponding output characteristics for 0.2 and 0.5 irradiances are shown in Fig. 13 and Fig. 14 respectively.

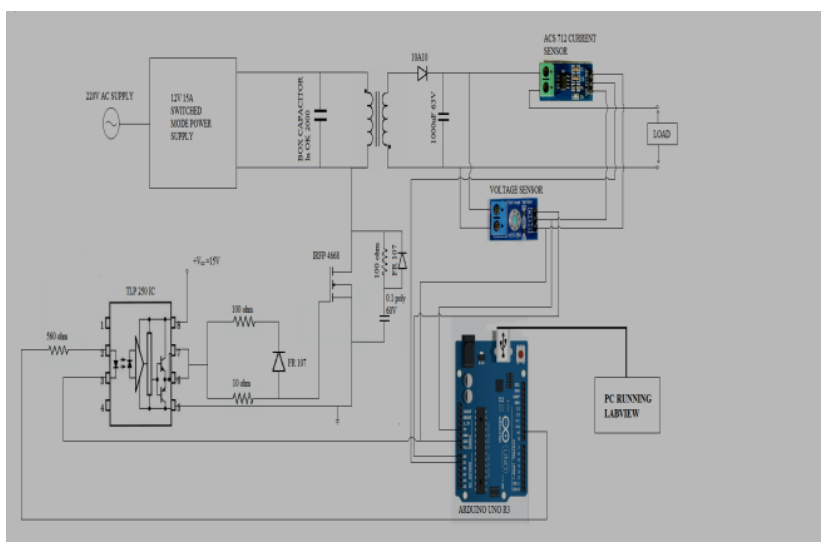

Fig. 6 .Circuit Diagram of Proposed System

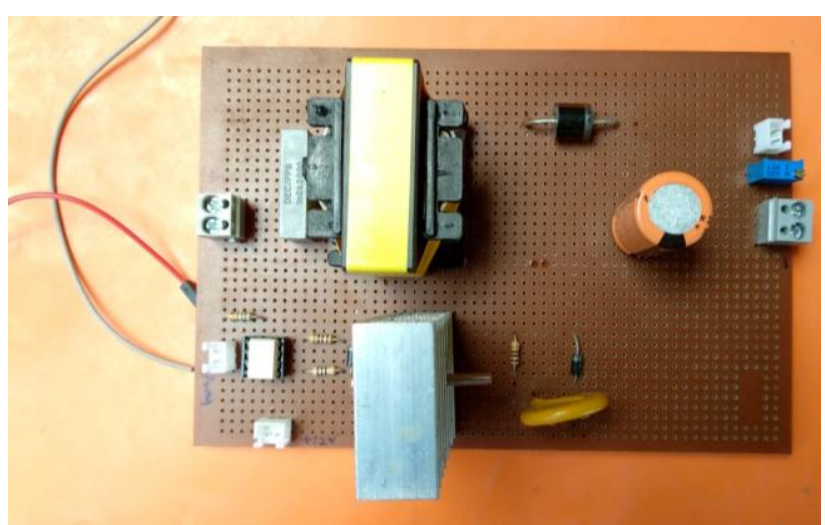

Fig. 7 .Flyback Converter Circuit

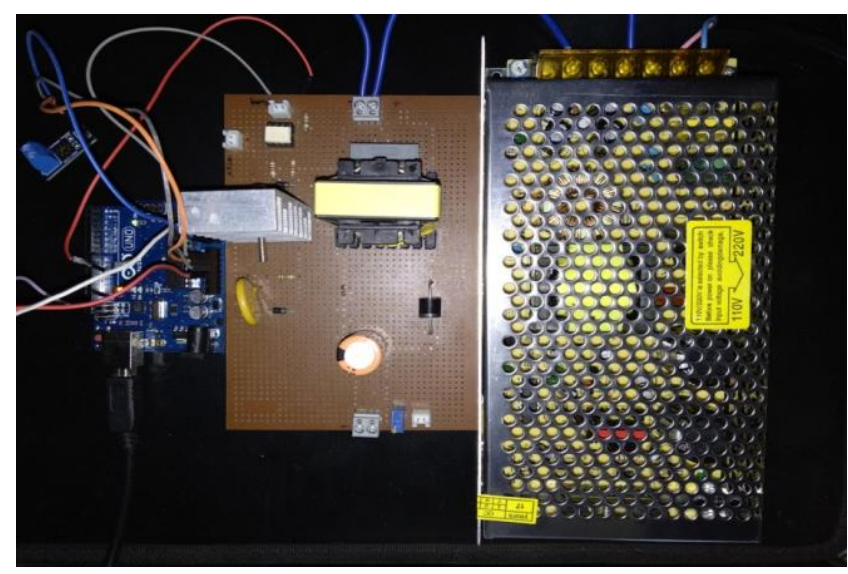

Fig. 8 .Hardware Circuit Components

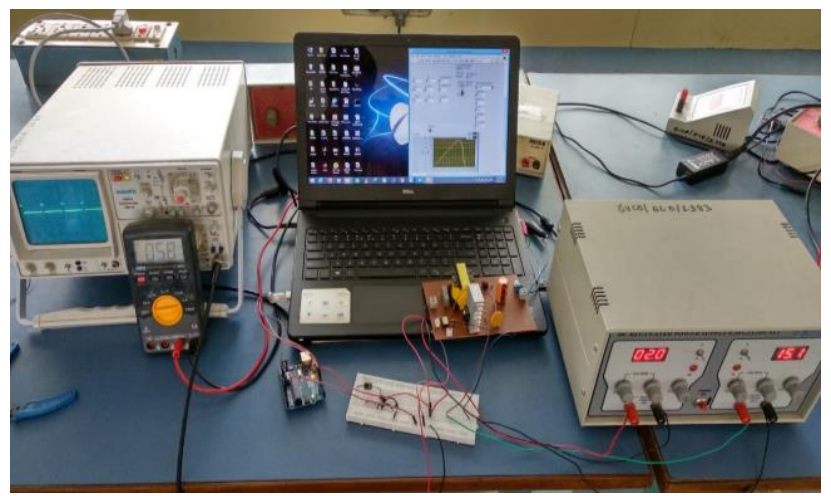

Fig. 9 .Complete Hardware Model

Published By:

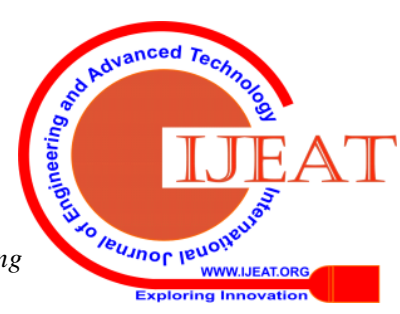




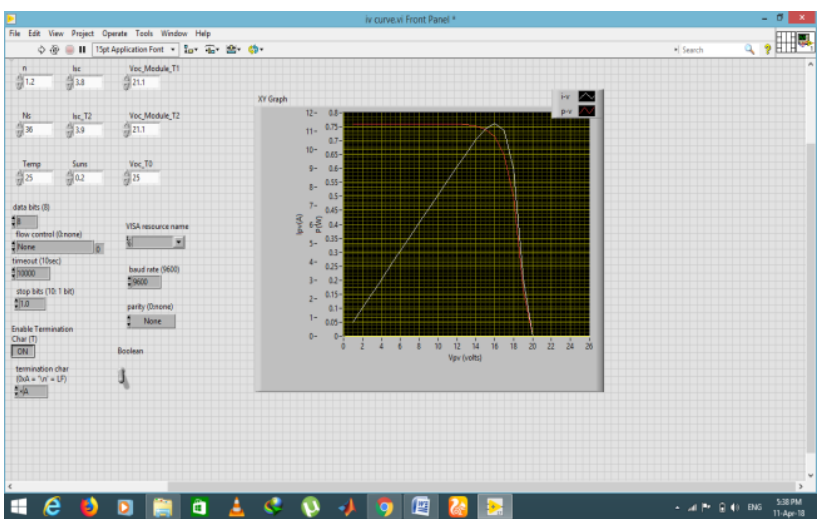

Fig. 10 .Panel Characteristics for 0.2 Irradiance

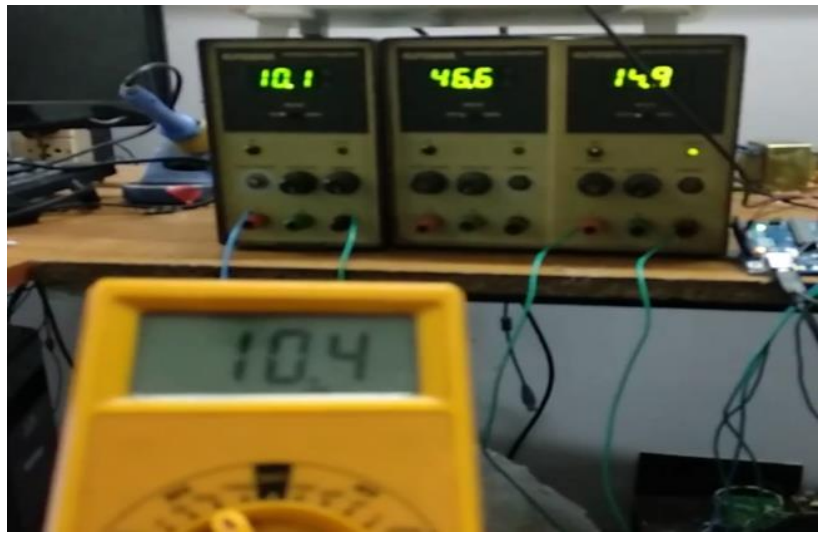

Fig. 11 .Open Circuit Voltage Obtained for 0.2 Irradiance

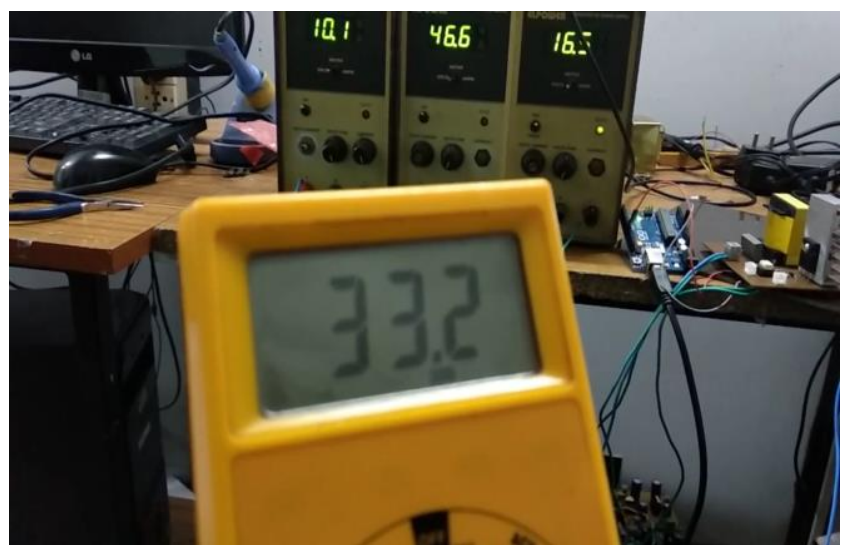

Fig. 12 .Open Circuit Voltage Obtained for 0.5 Irradiance

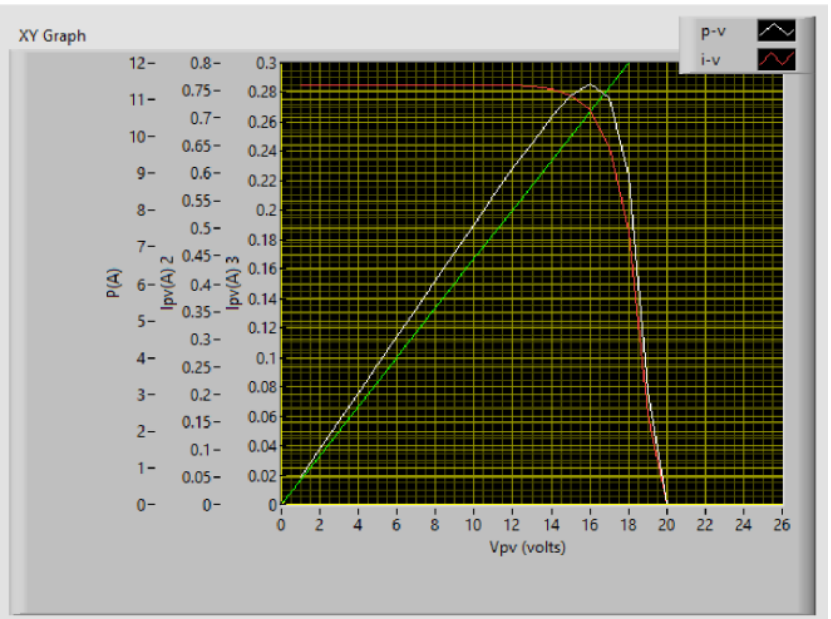

Fig. 13 .Output characteristics for 0.2 Irradiance

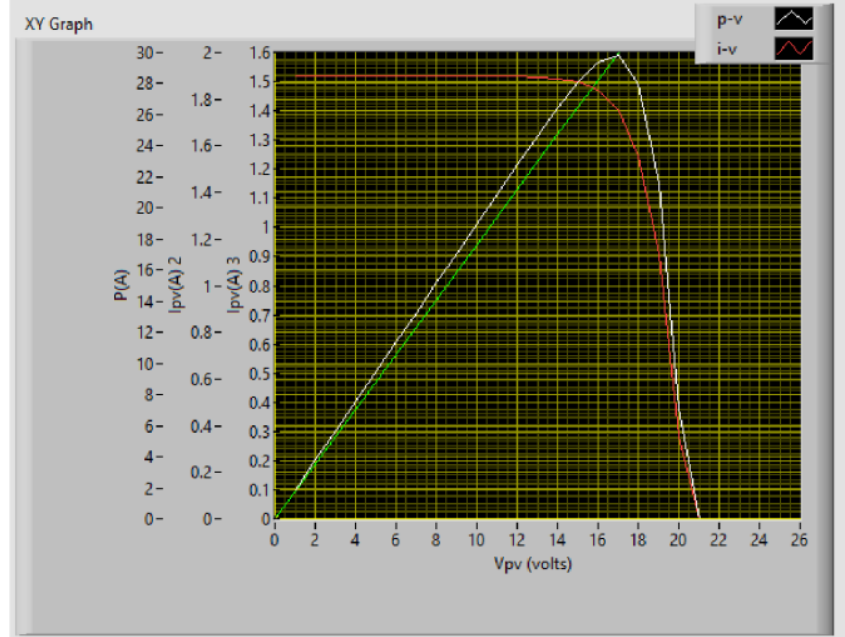

Fig. 14 .Output characteristics for 0.5 Irradiance

\section{CONCLUSION}

In this project, a simple and low-cost PV simulator based on LabView and Arduino has been proposed. Matlab simulation results and hardware results are presented which demonstrate the feasibility of such a scheme. The proposed system can not only be used as a testing device for MPPT algorithms, Inverters, Charge controllers, etc., but also as a tool to analyze newly developed solar panel modules for checking their characteristics. The proposed solar panel emulator can be used for experimental purposes as well as in educational institutions for teaching and demonstration. As an extension of this work, real time variations in environment can also be modeled and integrated with the proposed design. The range of operation can be increased by replacing the flyback converter with any other high power converter.

\section{REFERENCES}

1. D.M.K. Schofield, M.P. Foster and D.A. Stone, "Low-cost solar emulator for evaluation of maximum power point tracking methods" Electronics Letters, Vol.47, No.3, 2011.

2. D. Ickilli, H. Can, and K. S. Parlak, 'Development of a FPGA based photovoltaic panel emulator based on a DC/DC converter', in Photovoltaic Specialists Conference (PVSC), 38th IEEE conference,2012, pp.1417-1421.

3. D. S. L. Dolan, J. Durago, and Taufik, (2011) 'Development of a photovoltaic panel emulator using LabView', in PhotovoltaicSpecialists Conference (PVSC), 37th IEEE, 2011, pp.1795-1800.

4. R. G. Wandhare and V. Agarwal, 'A low cost, light weight and accurate photovoltaic emulator', in Photovoltaic Specialists Conference (PVSC), 37th IEEE, 2011, pp. 1887-1892.

5. A.Xenophontos, J. Rarey, A. Trombetta, and A. M. Bazzi, 'A flexible Low-cost photovoltaic solar panel emulation platform', in Power and Energy Conference at Illinois (PECI), 2014, pp. 1-6.

6. Ahmed Sanaullah \& Hassan Abbas khan, 'Design and Implementation of a low cost solar panel emulator”, IEEE 42nd Photovoltaic Specialist Conference (PVSC), 2015.

7. G. M. Tornez-Xavier, F. Gomez-Castaneda, J. A. Moreno Cadenas, and L. M. Flores-Nava, (2013) 'FPGA development and implementation of a solar panel emulator', in Electrical Engineering, Computing Science and Automatic Control (CCE), 10th International Conference on, 2013, pp. 467-472.

8. M. N. Qaiser, M. Usama, B. Ahmad, M. A. Tariq, and H. A. Khan, 'Low cost, robust and efficient implementation of MPPT based buck-boost converter for off-grid PV applications', in $40^{\text {th }}$ IEEE Photovoltaic Specialist Conference (PVSC), 2014, pp. 3701-3706.

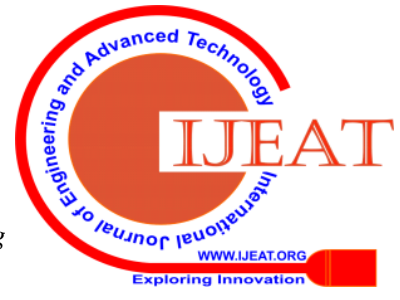


9. Murat Unlu, Sabri Camur, 'A Simple Photovoltaic Simulator Based on a One-Diode Equivalent Circuit Model', in IEEE 4th International Conference on Electrical and Electronics Engineering, 2017.

10. Prateek Garg, Priyanshi and Bhuvaneswari G, 'Power Electronic Circuit Based Implementation of a Solar PV Emulator Using a Power Factor Corrected Buck Converter', IEEMA Infinite conference, 2018.

\section{AUTHORS PROFILE}

Suganthi $\mathbf{K}$ received her B.E degree from Bharathiar University, Coimbatore in 2001 and M.E in Power Electronics and Drives in 2011. She is pursuing Ph.D in Anna University, Chennai. She is currently working as a Assistant Professor in Sri Venkateswara College of Engineering, Chennai. Her areas of interest include DCDC converters, Electrical Machines \& drives and application of power electronics to solar systems.

K. Sundararaman obtained his MS degree from the Indian Institute of Technology, Madras, in 1987. He worked at L\&T Ltd, \& Siemens Ltd. until 2003. He obtained his Ph.D degree from Anna university in 2015. He is currently a Professor in Rajalakshmi Institute of Technology, Chennai. His research interests are dc-dc converters \& renewable energy systems. 